\title{
Is 21st century neuroscience too focussed on the rat/mouse model of brain function and dysfunction?
}

\section{Paul R. Manger, *, Jessica Cort', Naseem Ebrahim ${ }^{1}$, Adelaya Goodman', Justine Henning ${ }^{1}$, Mohamed Karolia' ${ }^{1}$ Stacey-Lee Rodrigues ${ }^{1}$ and Goran Štrkalj ${ }^{2}$}

'School of Anatomical Sciences, Faculty of Health Sciences, University of the Witwatersrand, Johannesburg, Republic of South Africa

2 Department of Health and Chiropractic, Macquarie University, Sydney, Australia

Edited by:

Patrick R. Hof, Mount Sinai School of

Medicine, USA

Reviewed by:

Chet Sherwood, George Washington

University, USA

Nenad Sestan, Department of

Neurobiology, School of Medicine,

Yale University, USA

Zoltán Molnár, University of Oxford, UK

*Correspondence:

Paul R. Manger, School of Anatomical

Sciences, Faculty of Health Sciences,

University of the Witwatersrand, 7York

Road, Parktown, 2193 Johannesburg,

Republic of South Africa. e-mail:

Paul.Manger@wits.ac.za
Studies in the basic neurosciences are heavily reliant upon rat and mouse models. The brain is one of the most distinguishing features of the human species, but is enough being done to fully understand the evolution of the human brain and brain diversity in general? Without a clear understanding of the evolution of the nervous system we may be investing a great deal of effort into some limited specific animal models that may prove to be erroneous in terms of the overall usefulness in clinically applied research. Here we present an analysis that demonstrates that $75 \%$ of our research efforts are directed to the rat, mouse and human brain, or $0.0001 \%$ of the nervous systems on the planet. This extreme bias in research trends may provide a limited scope in the discovery of novel aspects of brain structure and function that would be of importance in understanding both the evolution of the human brain and in selecting appropriate animal models for use in clinically related research. We offer examples both from the historical and recent literature indicating the usefulness of comparative neurobiological investigation in elucidating both normal and abnormal structure and function of the brain.

Keywords: animal models, vertebrate, invertebrate, central nervous system, evolution

\section{INTRODUCTION}

In 1973 Dobzhansky penned an insightful title for an article: "Nothing in biology makes sense except in the light of evolution" (Dobzhansky, 1973). This particular title, while applying to all parts of the body of all life-forms, is salient to all comparative neuroscientists, and should be to those that use animal models to investigate human mental illness or basic brain functions.

As humans (Homo sapiens) one of the most prominent features that distinguishes us as a species is the organization and functioning of the brain. In order to fully understand ourselves, in the normal and abnormal condition, we must get to grips with this organ, its anatomy, physiology, molecular biology, cognitive processes, evolution, and the resultant behavioural states it produces (all 100 billion neurons, Blinkov and Glezer, 1968). While several advances have been made towards our understanding of the evolution of the human brain, it is only from concerted efforts to reveal evolutionary processes as they relate to the brain, that a full understanding of this distinguishing feature of humanity will emerge (e.g. Bullock, 1984, 1993; Nieuwenhuys, 1994; Shimizu, 2004).

If one briefly peruses table of contents of most general neuroscience journals it becomes obvious, very rapidly, that the majority of studies conducted are performed on either rats or mice, with humans as a close second. Studies on other species are more limited, especially those species that may be regarded as more exotic (those being geographically distant to the United States and European Union). It was our aim here to quantify the proportion of journal space dedicated to the various species that form the objects of scientific study. We analysed publications in the basic neurosciences (to the exclusion of the clinical neurosciences) from 12 general neuroscience journals covering a variety of specializations for the years
2000-2004, plus two journals that specifically target the comparative neuroscience community (Brain, Behavior and Evolution and The Journal of Comparative Neurology) over the period 1975-2004. In doing this we felt that a realistic projection of the species used in the modern basic neurosciences can be developed. We hope that the data presented here will provoke discussion among neuroscientists regarding our understanding of human brain evolution, evolutionary processes as they relate to the neural phenotypes of species (particularly in line with the burgeoning comparative genomic databases), and the use of appropriate animal models in the study of human mental illness and basic brain functions.

\section{MATERIALS AND METHODS}

We used the freely available database found at PubMed (http://www. ncbi.nih.gov, "A service of the National Library of Medicine and the National Institutes of Health") to create our specific database for analysis. The various features available on this website allowed us to extract information on each paper from the various journals examined. This information included the year of publication, the number of pages in each publication and the species examined. This data, along with the journal title, was entered into an Excel spreadsheet for further analysis.

To select journals, we chose randomly from the "Neurosciences" list available at the ISI Web of Knowledge (http://portal.isiknowledge.com). We excluded journals from the random selection process if the journal only published studies based on humans (such as those that publish case studies, or those focussing on neurosurgery), resulting in our selecting 12 journals from a group of 154. The journals examined under the "general neuroscience journal" category included: Archives Italiennes de Biologie [Impact 
Factor $(\mathrm{IF})=0.569$, as found on the ISI Web of Knowledge, Journal Citation Reports, Thomson Scientific in December, 2005], Behavioral Neuroscience $(\mathrm{IF}=2.819)$, Cerebral Cortex $(\mathrm{IF}=5.322)$, Glia $(\mathrm{IF}=4.781)$, International Journal of Neuroscience $(\mathrm{IF}=0.654)$, Journal of Chemical Neuroanatomy (IF =1.879), Journal of Comparative Physiology A ( IF = 2.016), Journal of Neuroscience Research (IF = 3.727), Journal of Sleep Research (IF = 3.400), Neuron $($ IF $=14.439)$, Neuroscientist $($ IF $=3.175)$, and Somatosensory and Motor Research $(\mathrm{IF}=0.953)$. These general neuroscience journals covered a range of sub-disciplines and of IFs. We also examined two journals in our "specific neuroscience journals" group, these being Brain, Behavior and Evolution (IF = 1.954) and The Journal of Comparative Neurology (IF $=3.400)$, as a search of neuroscience journals revealed these two journals appear to be those most specifically targeting the publication of comparative neuroscience studies.

We arranged the published articles into various groupings based on phylogenetic relationships, these groupings included: humans (Genus: Hominid), macaque monkeys (Genus: Macaca), other primates (Order Primates excluding Hominid and Macaca), rat and mouse (Genus: Rattus and Mus), domestic cat (Felis domesticus), other mammals (excluding the aforementioned groups), birds (Class: Aves), reptiles (Class: Reptilia), amphibians (Class: Amphibia), fish (Class: Pisces), and invertebrates (all species). This grouping of species proved to be useful in our analyses and comparisons.

Data was extracted from PubMed for the period 2000-2004 for all 14 journals. For the two specific neuroscience journals, data was extracted from 1975 to 2004 and subdivided into 5-year blocks (i.e. 1975-1979, 1980-1984, etc.). These data were then plotted using the features of Excel for comparisons. All differences described herein were found to be statistically significant using a Chi-squared test.

Published articles were included for analysis if we could readily find the year of publication, the number of pages in the study and the name of the species used (common or Latin). Published articles were excluded from the analysis if the year and page numbers were not available, or if the species name could not be found in either the title of the article or the abstract of the article (these did not occur on a regular basis). Our major causes for exclusion of an article were when the article was a review not based on a specific species (frequent occurrence), or if the study included animals from more than one of our groupings (frequent occurrence). Due to these exclusion criteria, a total of 1,095 articles were processed for Brain, Behavior and Evolution (from 1,279 on the PubMed website, $14.4 \%$ exclusion rate), 10,903 articles were processed for The Journal of Comparative Neurology (from 12,169 on the PubMed website, $10.4 \%$ exclusion rate), and 4,922 from the general neuroscience journal group, giving a total of 16,920 articles $(7,364$ for the years 2000-2004) examined and analysed.

\section{RESULTS}

\section{THE PERIOD BETWEEN 2000 AND 2004}

The central finding of this analysis is that the majority of articles published in neuroscience are devoted to the rat and mouse. In the general neuroscience journal group, these two species accounted for $45 \%$ of the published pages in the journals (Figure 1, Table 1). A strong correlation between number of published pages and number

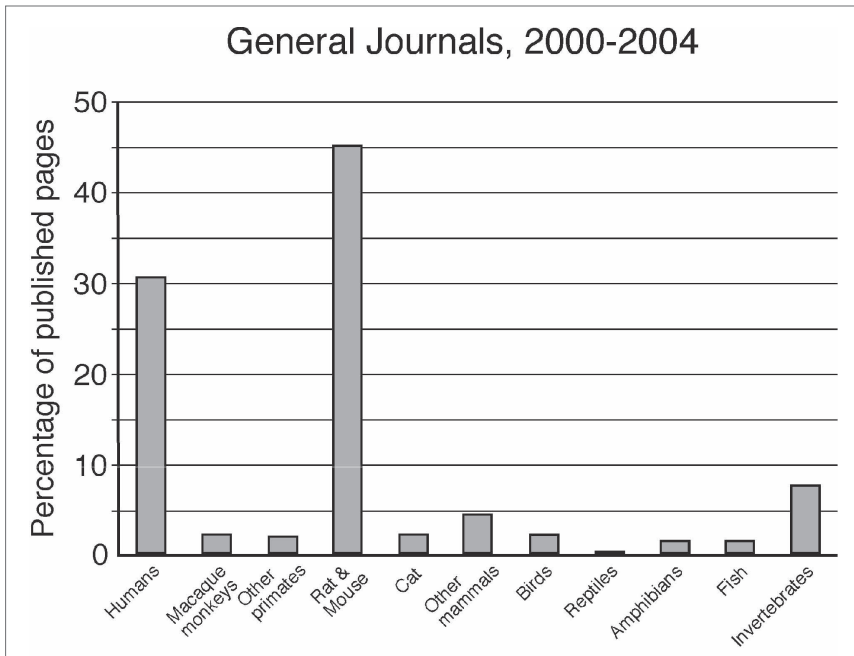

Brain, Behavior and Evolution, 2000-2004

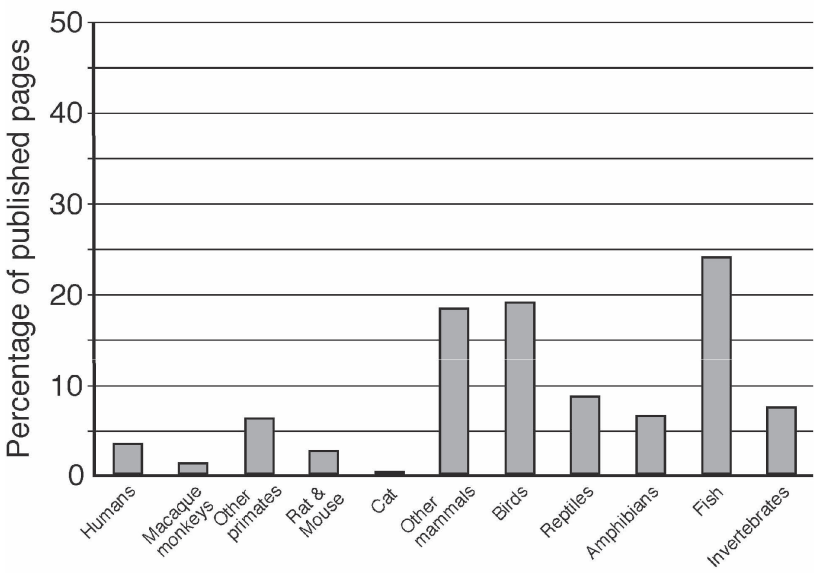

Journal of Comparative Neurology, 2000-2004

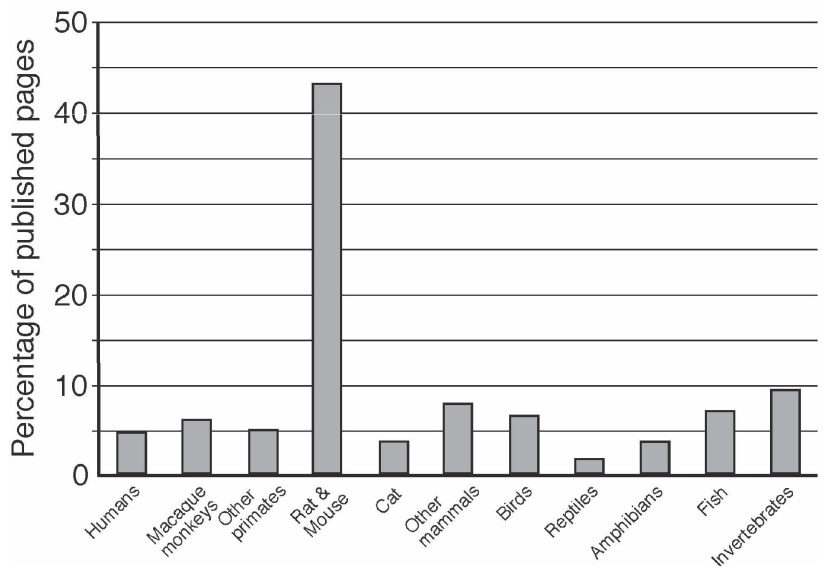

FIGURE 1 | Bar graphs representing the percentage of published pages devoted to each of the phylogenetic groupings classified in the present study for the period 2000-2004 in the general neuroscience group and in each of the two comparative journals. Note the similarity of The Journal of Comparative Neurology to the general neuroscience journals, and the emphasis of the under-represented groups in Brain, Behavior and Evolution. 


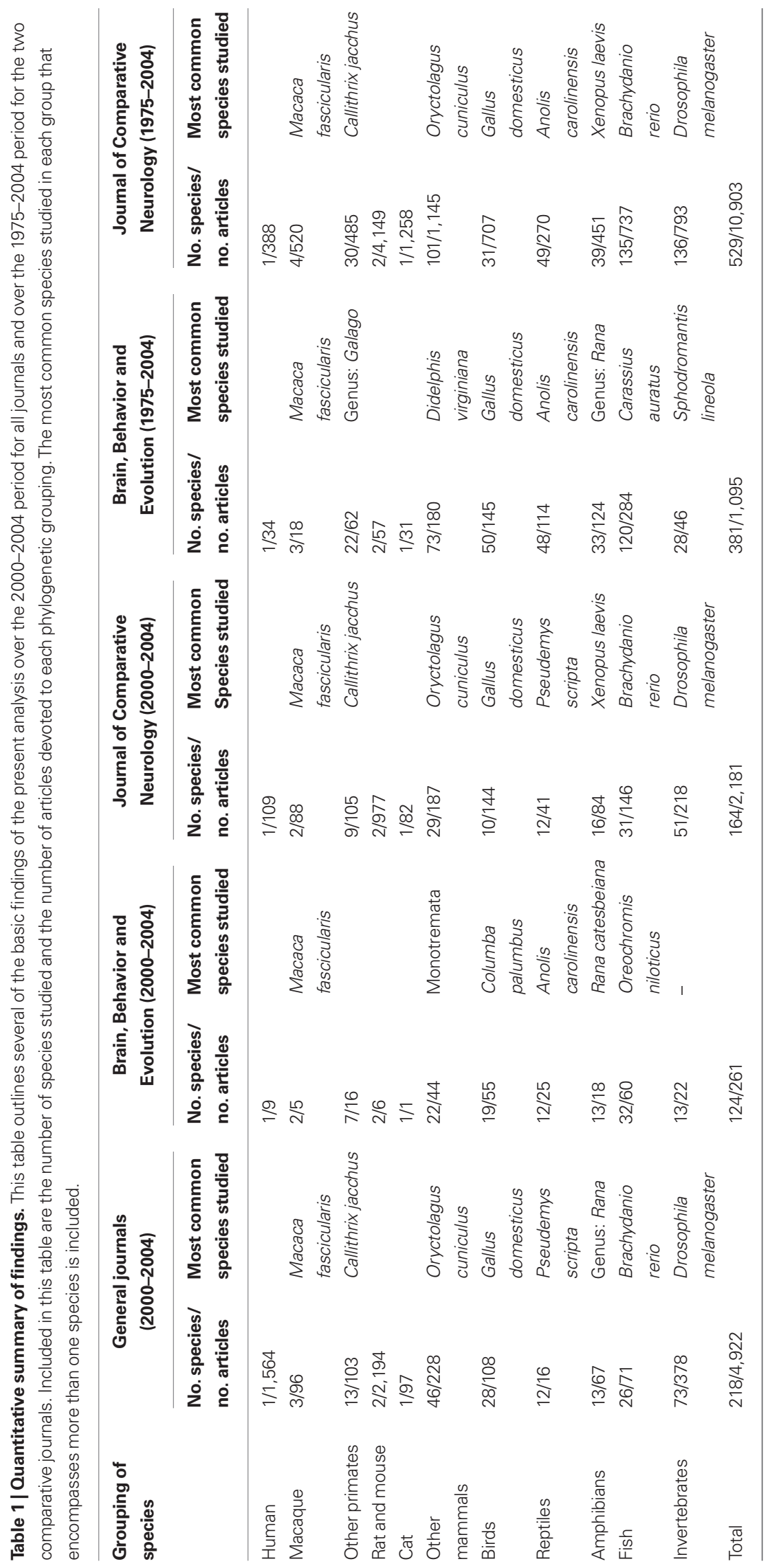


of published articles was found (using a Spearman's rank test we found $r=0.97$ ). If the keywords "rat AND brain" are entered into a PubMed search for the years 2000-2004 a total of 51,068 articles are located, if "mouse AND brain" are entered 24,149 articles are located, and if "brain" is entered 187,521 articles are located. The combined rat and mouse articles correspond to $40.1 \%$ of the articles published, which is a close approximate of our more refined data search based on total page numbers and with specific exclusion and inclusion criteria.

Humans were the second most numerous species used as an object of study, accounting for $30.7 \%$ of the published articles in the general neuroscience journal group (Figure 1, Table 1). This was followed by invertebrates $(7.9 \%)$, other mammals $(4.4 \%)$, cat (2.3\%), macaque monkeys $(2.2 \%)$, birds $(2.2 \%)$, other primates $(2.1 \%)$, fish $(1.5 \%)$, amphibians $(1.4 \%)$, and reptiles $(0.3 \%)$ (Figure 1).

For the period 2000-2004 in Brain, Behavior and Evolution, the majority of studies were devoted to the various species of fish (24.3\%) (Figure 1, Table 1). This was followed by birds (19.4\%), other mammals $(18.6 \%)$, reptiles $(8.6 \%)$, invertebrates $(7.7 \%)$, amphibians $(6.8 \%)$, other primates $(6.4 \%)$, humans $(3.6 \%)$, rat and mouse $(2.8 \%)$, macaque monkeys $(1.6 \%)$, and cats $(0.2 \%)$ (Figure 1). The result of the analysis of this journal indicates a clear difference in the phylogenetic grouping of the articles published to those published in the 12 general neuroscience journals. More pages of this journal are devoted to the groups of animals that do not occupy a great deal of page space in the general journals.

For The Journal of Comparative Neurology an again overwhelming majority of published pages were devoted to the rat and mouse (43.2\%) (Figure 1, Table 1). The second most numerous group was invertebrates $(9.3 \%)$, followed by other mammals $(8 \%)$, fish $(7.1 \%)$, birds $(6.8 \%)$, macaque monkeys $(6.2 \%)$, other primates (5.1\%), humans (4.8\%), amphibians (3.9\%), cat (3.7\%), and reptiles $(1.9 \%)$. For the most part, the relative occupation of the published pages of The Journal of Comparative Neurology followed the pattern established in the general neuroscience journals (Figure 1). The one major difference was the lack of pages devoted to studies of the human brain in this journal, allowing a slightly higher proportion of published pages to be devoted to the other groups.

\section{THE PERIOD 1975-2004 IN BRAIN, BEHAVIOR AND EVOLUTION AND THE JOURNAL OF COMPARATIVE NEUROLOGY}

We analysed the number of pages devoted to the various groups in blocks of 5 years ranging from 1975 to 2004 for both these journals regarded as specific to comparative neuroscience. For Brain, Behavior and Evolution there was a great deal of quinquennial variation in the proportion of the journal occupied by each group (Figure 2), but it appears as though there are some trends towards decreasing the amount of page space devoted to macaque monkeys (from $5.4 \%$ in $1975-1979$ to $1.6 \%$ in $2000-2004$ ), rat and mouse (from $23.4 \%$ in $1980-1984$ to $2.8 \%$ in $2000-2004$ ), and cat (from $11.8 \%$ in $1980-1984$ to $0.2 \%$ in $2000-2004$ ) over this 30 -year period. There also appears to be a trend towards an increasing number of pages devoted to studies of the invertebrate nervous system (from 0\% in 1975-1979 to 7.7\% in 2000-2004). The most obvious difference over this 30 -year period was the substantial increase in pages devoted to studies of the fish nervous system in the years 1985-1999, occupying an average of $36.9 \%$ of the published journal pages. The other groups had various averages over this period (humans $-3.2 \%$, other primates $-5.7 \%$, other mammals $-17.2 \%$, birds $-12.9 \%$, reptiles $-8.4 \%$, amphibians $-10.6 \%$ ).

For The Journal of Comparative Neurology small trends for increasing pages of the journal were noted for humans (from $1.3 \%$ in $1975-1979$ to $4.8 \%$ in $2000-2004$ ) and invertebrates (from $3.9 \%$ in $1975-1979$ to $9.3 \%$ in 2000-2004) (Figure 2). A significant increase in the number of pages devoted to studies of the rat and mouse brain was observed over this 30 -year period (from $26.5 \%$ in $1975-1979$ to $43.1 \%$ in $2000-2004$ ). The only substantive negative temporal trend was associated with cats, where the percentage of journal pages devoted to this group fell from 26\% in 1975-1979 to $3.8 \%$ in $2000-2004$. The remainder of the groups remained at relatively stable levels during this period (macaque monkeys - average $6 \%$, other primates $-5.3 \%$, other mammals $-10.7 \%$, birds $-6.4 \%$, reptiles $-2.7 \%$, amphibians $-3.8 \%$, fish $-6.5 \%$ ).

\section{DISCUSSION \\ SELECTION AND SIZE OF THE SAMPLE}

The analysis presented here may be skewed by various factors including the size and selection of the sample based on the exclusion and inclusion criteria for individual journals and the published articles within those journals. In the present case we used a randomly selected subset of published journals, classified the articles published in these, and aimed to draw conclusions regarding the broader scope of publication practices in the basic neurosciences. On the ISI website we found a total of 154 journals that may be considered basic neuroscience journals, i.e. they are not based in the purely clinical neurosciences and publish studies using nonhuman animals. The exclusion of the clinical neuroscience journals may mean that a lesser proportion of human studies are included in our sample and thus may be under-represented in our projections from our data to the neurosciences in general, but this would not affect our projection to the basic neurosciences, which was the aim of this study.

The size of our sample may also come under scrutiny. In the present study we classified published articles from 14 journals from a possible total of 154 , or $\sim 9 \%$. In terms of the total number of published articles, $\sim 124,900$ article can be found on PubMed from the 154 basic neuroscience journals for the years 2000-2004; our sample of 7,364 articles represents $\sim 5.9 \%$ of this total number. While it is clear that a larger sampling of the published articles will lead to a more accurate, or refined, reflection of the proportion of publications amongst the phylogenetic groupings outlined in this study, we feel that what we have presented here is a fair representation of the total possible pool of publications. Thus, we conclude that our results can be extrapolated, with a reasonable degree of accuracy, to the entire pool of basic neuroscience publications.

\section{UNDERSTANDING BRAIN EVOLUTION}

One of the central issues that the present study addresses is whether the basic neuroscientific community is doing enough to understand brain evolution, both events and processes. As mentioned above, the brain is possibly the most distinguishing characteristic of modern Homo sapiens, and as such, any complete understanding of the place of modern humans in the Kingdom Animalia requires 


\section{Brain, Behavior and Evolution, 1975-2004}

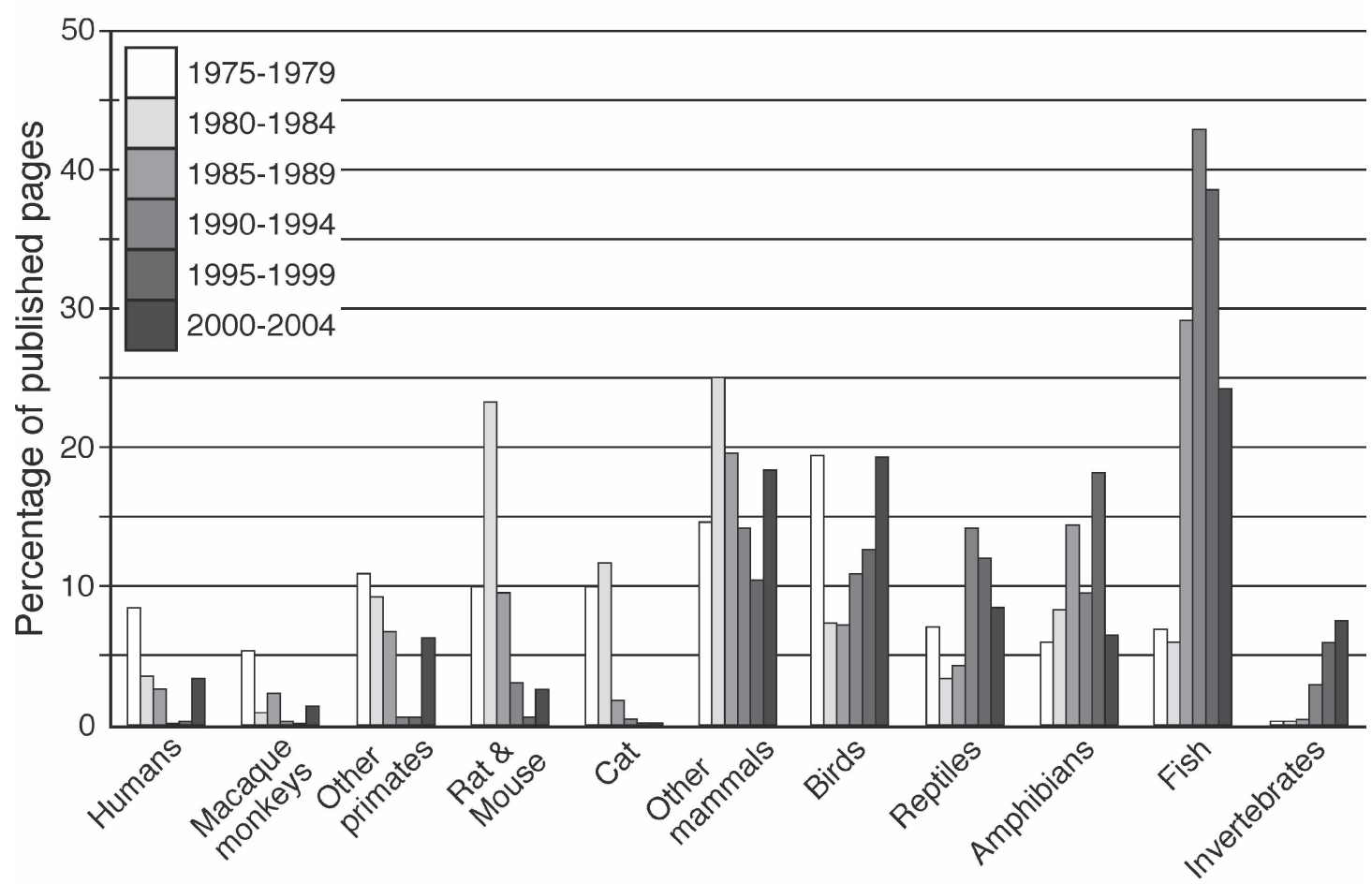

Journal of Comparative Neurology, 1975-2004

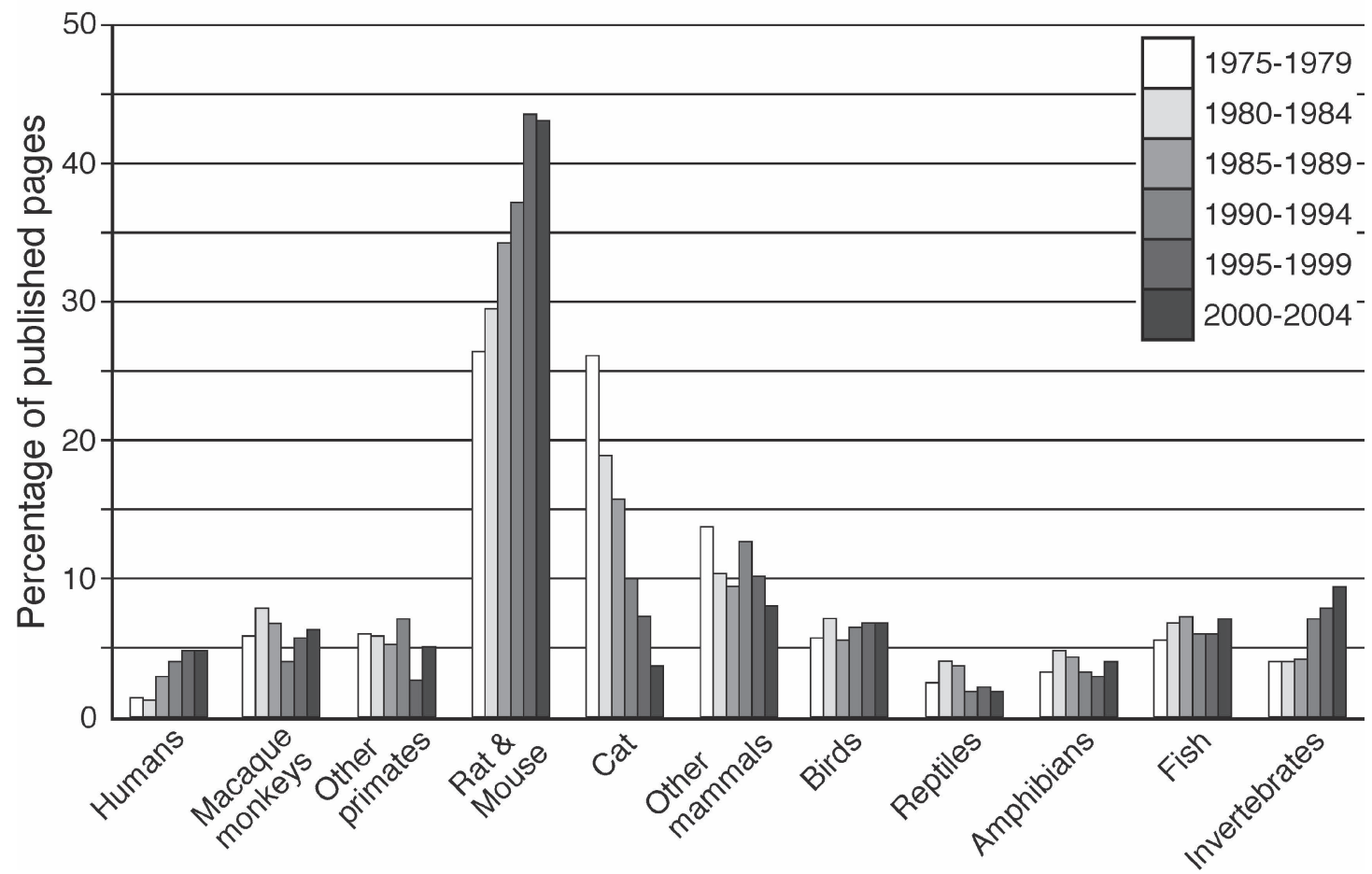

FIGURE 2 | Bar graphs representing the percentage of published pages devoted to each of the phylogenetic groupings classified in the present study in 5-year blocks for the period 1975-2004 in each of the two comparative journals. Specific trends in the animal species studied can be seen in these plots. 
a detailed knowledge of human brain evolution. Given that the modern human brain evolved subject to evolutionary pressures and processes, the heavy bias of study towards rats and mice and humans ( $\sim 75 \%$ of the total effort) indicates that research towards understanding human brain evolution may be under-represented.

Similarly, we can postulate that a minority of effort is directed towards understanding evolution of the brain in general. Given that $\sim 95 \%$ of all animal species are invertebrates and that fish represent $47 \%$ of the vertebrate radiation, it appears reasonable to conclude that little effort is being made to understand brain diversity on the broader scale. Rather, it appears that the majority of effort is directed towards understanding the brains of three eutherian mammal species - which represents a tiny fraction of a percentage (about $0.0001 \%$ ) of the total diversity of nervous systems.

This bias towards three mammalian species may be explained by the heavy emphasis on the study of human mental illnesses. It appears reasonable to posit that the majority of work done on the brain of the rat or mouse is directed towards revealing mechanisms of brain function and dysfunction that relate to human mental illness or disorders rather than an underlying curiosity regarding the brain and behaviour of these laboratory rodents. One potential problem with this bias is that we do not appear to understand, or appear to be making a concerted effort to understand, the differences in rodent and human brains resulting from the evolutionary processes leading to the extant morphotypes in these species. Is it then prudent to routinely extrapolate findings from laboratory rodent brains to humans? One recent interesting example of the potential problem of limiting studies to rats to extrapolate to humans was the finding of extended sleep deprivation being lethal to rats (Rechtschaffen and Bergmann, 2002). Later studies have found different physiological responses and lack of lethality in response to sleep deprivation in humans and many other animals, including the closely related mouse (reviewed in Siegel, 2008).

\section{TRENDS IN ANIMAL SPECIES USED IN THE COMPARATIVE JOURNALS}

The present analysis of publications in the two comparative journals revealed several trends in publication practices. In both journals there were decreases in the percentage of pages devoted to studies of the brain of the cat. This was the only trend common to both journals. This indicates that it is likely that there is a general trend across the basic neurosciences for a decreased use of cats in experiments. In fact, if one examines the number of articles devoted to cats using the search "cat AND brain" in PubMed we see a steady decline in the use of cats over the last 30 years, from a total of 6,329 articles in 1975-1979, down to 2,406 articles in 2000-2004. It is possible that this trend is related to social factors such as pressures from anti-vivisection groups.

In The Journal of Comparative Neurology we see a trend for an increase in the number of pages devoted to studies of the brain of the rat and mouse. The percentage of this journal devoted to this phylogenetic group closely allies that found in our general neuroscience journal group. This trend is paralleled by a basic search in PubMed, where the total number of articles located for "rat AND brain" + "mouse AND brain" for the years 1975-1979 was 28,738, and for the years 2000-2004 was 75,217. This dramatic difference must of course be tempered in its interpretation by the understanding that the number of journals and number of published pages has increased over this period, but it does appear likely that the trend shown in The Journal of Comparative Neurology reflects a wider trend in the basic neurosciences. This increase in the number of studies devoted to the rat and mouse may be related to changing social views regarding animal experimentation, the ease of acquiring and breeding rats and mice, and the possibility of genetic manipulation of these species.

The last trend of specific interest to mention is that of the increased percentage of pages devoted to studies of the brain of fish species in Brain, Behavior and Evolution during the 15-year period of 1985-1999. Brain, Behavior and Evolution is not a large journal, being published once monthly, with $<10$ articles per month, with $\sim 60-65$ pages. What might explain this peak in publications related to fish? For the majority of this 15 -year period, $\mathrm{R}$. Glenn Northcutt was the Editor-in-Chief of Brain, Behavior and Evolution. Approximately 70\% of Northcutt's publications (as revealed through an author search on PubMed) are experimental studies of the brain of various fish species. While Brain, Behavior and Evolution is a small journal, it is a major contributor in the publication of studies that do not focus upon the rat, mouse, or human. Northcutt's personal emphasis on the study of fish brains may have been a major influence in the increased percentage of this journal devoted to studies of the fish during this period (something of which I am sure he is quite rightly proud!). In a field that appears to be as small as comparative neuroscience is, it is clear that a single person can have a significant influence on the field.

\section{WHY STUDY BRAINS OF VARIOUS SPECIES?}

While our results indicate limited page space devoted to the study of the brain of a variety of species, we must raise the question of whether studying a range of species is a valuable tool in basic neuroscience in and of itself without reference to understanding brain evolution. It is our contention here, that both historically and recently, comparative studies have added tremendously to our understanding of the basic function and structure of the nervous system.

Historical examples of the benefit of comparative neurobiological studies include:

a. The squid giant axon and the ionic basis of the action potential (Hodgkin and Huxley, 1952).

b. The discovery of dendritic spines in the central nervous system (CNS) of the chicken (Cajal, 1888).

c. The discovery of the reflex arc in frogs (Hall, 1833).

d. The discovery of conditioned reflexes in dogs (Pavlov, 1927) and operant conditioning in pigeons (Skinner, 1938).

e. The parcellation of the cerebral cortex into motor (Fritsch and Hitzig, 1870) and visual (Munk, 1878) areas in the dog.

Recent examples of the benefit of comparative study include:

a. Understanding the cellular basis of learning and memory in Aplysia (Kandel, 2004).

b. The discovery of neuronal replacement in the adult nervous system in canaries (Nottebohm, 2002).

c. The discovery of neuronal regeneration in freshwater planarians (Platyhelminthes) (Saló, 2006).

d. The revelation of the visual receptive field in Limulus (Wolbarsht and Yeandle, 1967). 
e. The discovery of nerve growth factor in the chicken (Bueker, 1948).

f. Understanding cortical columnar organization, development and plasticity in cats and monkeys (Hubel and Wiesel, 1998; Mountcastle, 1997).

g. The discovery of radial neuronal migration in macaque monkey (Rakic, 1990).

h. The unravelling of spinal cord intrinsic circuitry for locomotion in lamprey (Grillner, 1985).

i. The discovery of representational plasticity in the adult cerebral cortex following peripheral perturbations in monkeys (Merzenich et al., 1983, 1984).

j. The discovery of reward signalling by midbrain dopaminergic neurons in monkeys (Schultz, et al., 1993, 1997).

All these examples indicate the usefulness of examining a range of extant nervous systems in the discovery of basic principles in the function and dysfunction of the nervous system. The examination of the CNS of various species may lead to opportunities to reveal features that are not readily discernable in the rodent and human brains. It is apparent even from this brief survey of the advances in understanding made through the use of non-standard laboratory animals that much can be discovered and understood that may have been otherwise missed. Taken in this sense,

\section{REFERENCES}

Blinkov, S. M., and Glezer, I. I. (1968). The Human Brain in Figures and Tables. A Quantitative Handbook. New York, Plenum Press.

Bueker, E. D. (1948). Implantation of tumors in the hind limb field of the embryonic chick and the developmental response of the lumbosacral nervous system. Anat. Rec. 102, 369-390.

Bullock, T.H.(1984). Comparative neuroscience holds promise for quiet revolutions. Science 225, 473-478.

Bullock, T.H. (1993). How are more complex brain different? One view and an agenda for comparative neurobiology. Brain Behav. Evol. 41, 88-96.

Cajal,S.R. (1888). Estructura de los centros nerviosos de las aves. Rev. Trimest. Histol. Norm. Patol. (Barcelona) 1, 1-10.

Dobzhansky, T. (1973). Nothing in biology makes sense except in the light of evolution. Am. Biol. Teach. 35, 125-129.

Fritsch, G., and Hitzig, E. (1870). Uber die elektrische Erregbarkeit des Grosshirns. Arch. Anat. Physiol. Wiss. Med. 37, 300-332.

Grillner, S. (1985). Neurobiological bases of rhythmic motor acts in vertebrates. Science 228, 143-148.

Hall, M. (1833). On the reflex function of the medulla oblongata and medulla spinalis. Philos. Trans. R. Soc. Lond., B, Biol. Sci. 1833, 635-665.

Hodgkin, A. L., and Huxley, A. F. (1952). A quantitative description of membrane current and its application to conduction and excitation in nerve. J. Physiol. 117, 500-544.

Hubel, D. H., and Wiesel, T. N. (1998). Early exploration of the visual cortex. Neuron 20, 401-412.

Kandel, E. R. (2004). The molecular biology of memory storage: a dialog between genes and synapses. Biosci. Rep. 24, 477-522.

Merzenich, M. M., Kaas, J. H., Wall, J., Nelson, R. J., Sur, M., and Felleman, D. (1983). Topographic reorganization of somatosensory cortical areas $3 \mathrm{~b}$ and 1 in adult monkeys following restricted deafferentation. Neuroscience 8, 33-55.

Merzenich, M. M., Nelson, R. J., Stryker, M. P., Cynader, M.S., Schoppmann, A., and Zook, J. M. (1984). Somatosensory cortical map changes following digit amputation in adult monkeys. $J$. Comp. Neurol. 224, 591-605.

Mountcastle, V. B. (1997). The columnar organization of the neocortex. Brain 120, 701-722.

Munk, H. (1878). Weitere Mittheilungen zur Physiologie der Grosshirnrinde. Verh. Physiol. Ges. Berl. 162-178.

Nieuwenhuys, R. (1994). Comparative neuroanatomy: place, principles,

comparative neurobiology may offer "short-cuts" in our expanding understanding of the brain.

\section{CONCLUSION}

The analysis undertaken here indicates that the efforts in basic neuroscience research are for the most part focussed on three species. It appears appropriate that a debate be opened regarding our investment into these species and the overall aims of the basic neurosciences including clinically based research. With the rapid increase in our knowledge of the complete genomes of many species, the accelerating pace of bioinformatics as a directive research tool, and the technical advances being made especially in molecular and developmental neuroscience, the study of species with phenotypes different to rats and mice may provide a powerful combination with these techniques that could lead to significant advances in our understanding of human neural disorders as well as human brain evolution. Given that any scientist working on an animal model that extrapolates their results to the human brain must accept the basic facts of evolution and the 80 million years since the last common ancestor of the Muridae and the Hominidae existed, do we actually know enough about brain evolution to ensure that these extrapolations are pragmatic and not just leaps of faith?

practice and programme. Eur. J. Morphol. 32, 142-155.

Nottebohm, F. (2002). Neuronal replacement in adult brain. Brain Res. Bull. 57, 737-749.

Pavlov, I. P. (1927). Conditioned Reflexes. London, Oxford University Press.

Rakic, P. (1990). Principles of neural cell-migration. Experientia 46, 882-891.

Rechtschaffen, A., and Bergmann, B. M. (2002). Sleep deprivation in the rat: an update of the 1989 paper. Sleep 25, 18-24.

Saló, E. (2006). The power of regeneration and the stem-cell kingdom: freshwater planarians (Platyhelminthes) Bioessays 28, 546-559.

Schultz, W., Apicella, P., and Ljungberg, T. (1993). Responses of monkey dopamine neurons to reward and conditioned stimuli during successive steps of learning a delayed response task. J. Neurosci. 13, 900-913.

Schultz, W., Dayan, P., and Montague, P. R. (1997). A neural substrate of prediction and reward. Science 275 1593-1599.

Shimizu, T. (2004). Comparative cognition and neuroscience: misconceptions about brain evolution. Jpn. Psychol. Res. 46, 246-254.

Siegel, J. M. (2008). Do all animals sleep? Trends Neurosci. 31, 208-213
Skinner, B. F. (1938). The Behavior of Organisms: An Experimental Analysis. New York, Appleton-Century-Crofts. Wolbarsht, M. L., and Yeandle, S. S. (1967). Visual processes in the Limulus eye. Annu. Rev. Physiol. 29, 513-542.

Conflict of Interest Statement: The authors declare that the research was conducted in the absence of any commercial or financial relationships that could be construed as a potential conflict of interest.

Received: 19 August 2008; paper pending published: 02 September 2008; accepted: 06 October 2008; published online: 12 November 2008

Citation: Manger PR, Cort J, Ebrahim N, Goodman A, Henning J, Karolia M, Rodrigues S-L and Štrkalj G (2008) Is 21st century neuroscience too focussed on the $\mathrm{rat} /$ mouse model of brain function and dysfunction? Front. Neuroanat. (2008) 2:5. doi: 10.3389/neuro.05.005.2008 Copyright (c) 2008 Manger, Cort, Ebrahim, Goodman, Henning, Karolia, Rodrigues and Strkalj. This is an open-access article subject to an exclusive license agreement between the authors and the Frontiers Research Foundation, which permits unrestricted use, distribution, and reproduction in any medium, provided the original authors and source are credited. 